技術ノート

\title{
指定レベルの濃淡印刷が可能な15階調中間色表示プログラム
}

\author{
山田 俊雄 $*$
}

\section{Program to Draw Simple Gray-scale Image in 15 Colors with Monochrome-printer}

\section{Toshio YAMADA*}

キーワード：中間色，濃淡印刷，BASIC

Key Words: Gray-scale, Monochrome-printer, BASIC

\section{1.はじめに}

身近かな問題をパソコンで処理することが当たり前のこ とになってきています。画像・図形の彩色もディスプレイ のうえで楽にできます.グラフィックに関する書籍も豊富 に出回っているので参考書にもこと欠きません．でも困っ たことが一つあります．色美しく解析結果を視覚化したつ もりでも，ディスプレイ表示だけならば良いのですが，印 刷すると真っ黒なシルエットしか出せないことです.

ドットプリンターでも，レーザープリンターでも，ディ スプレイ上での塗色 (ペイント) 効果を失わずに, 濃淡印 刷できる原理を紹介します。言語はN88BASICです。こ のプログラムは，ちょっと加工すれば，さらに中間色をい ろいろ出せます。

原理は BASIC のタイル機能を利用した簡単なものです. プログラムを走らせると, 15色までの濃淡サンプルがディ スプレイにでます．印刷すると濃淡階調のパターンになり ます。あなたのプログラムの中に組み込めば，三角・四角・
多角形でも, PAINT 命令で描かれたディスプレイ上の色 彩階調を，そのまま，PRINT OUTできます。

\section{2. 使 い方}

1000-1180行が注釈, 1190-1400行がメイン・プログラ ム, 20000台の行が主題のサブルーチン群（COLOR.TILES; RGB.COLOR;DEF.COLOR;DATA.T) です.

まず, このサブルーチン群を，あなたのプログラムに MERGE します.そして，あなたのプログラムの頭で (下の例では1260行のように）COLOR.TILES を呼んでおき ます。色塗りを使いたいところで, TILE\$(xx) とペイント するだけ (1320行) です.

1250行の入力で， 4 または 5 を指定すると中間色が試せ ます.サンプルを参考にタイルすれば，簡単に利用ができ ると思います．このプログラムの出力例を第 1 図に示して おきます。
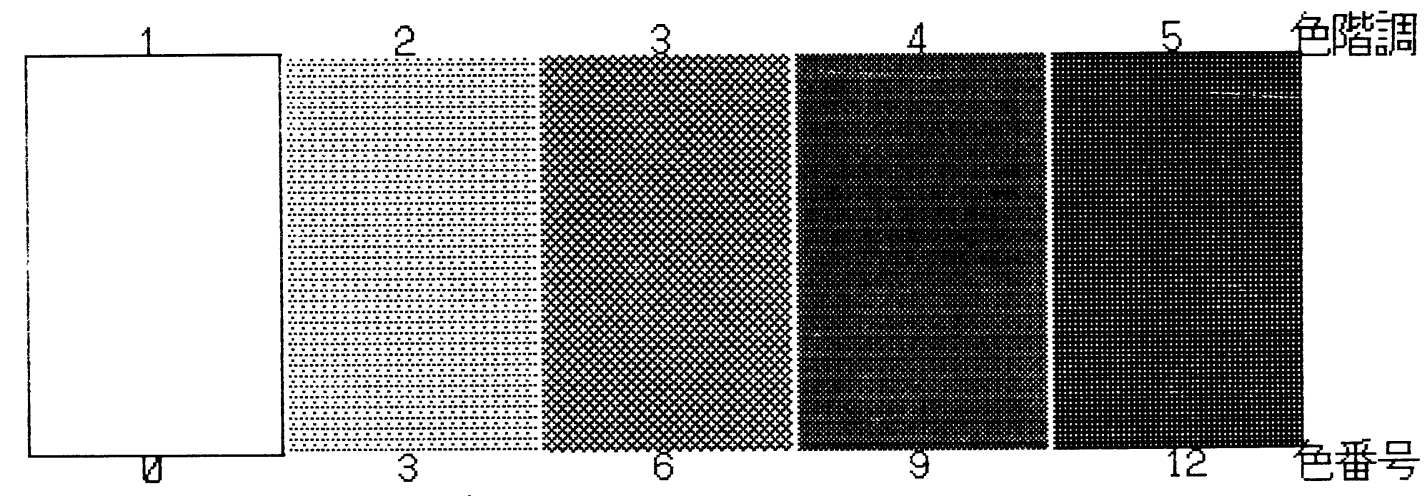

Press any key, to cont inue !

第 1 図 プログラム出力図例

\footnotetext{
* 2-12-3 Kishimachi, Urawa-shi, Saitama 336, Japan.
} 


\section{3. プログラム・リスト}

\begin{tabular}{|c|c|}
\hline \multicolumn{2}{|c|}{1000} \\
\hline 1010 & ..by $\mathrm{PC}-9801 \mathrm{VX}, \mathrm{FX}$. \\
\hline 1020 & \\
\hline 1030 & 。指定レベルの濃淡印刷が可能な \\
\hline 1040 & 15 階調 中間色 表示プログラム \\
\hline 1050 & \\
\hline 1060 & $1985,1992,1993 \ldots$ \\
\hline 1070 & \\
\hline 1080 & . [使い方 $]$ \\
\hline 1090 & . (1) まず, 次の 1 行を宣言します. \\
\hline 1100 & GOSUB *COLOR.TILES \\
\hline 1110 & . (2) つぎに, 20000行以下のサブルーチンを使って, \\
\hline 1120 & 変数 $\mathrm{R}, \mathrm{G}, \mathrm{B}$ のそれぞれに 0-10 の值を与えると \\
\hline 1130 & . (3) 自動的に, TILES によって 濃淡構造の中間色が PAINT される. . \\
\hline 1140 & （ SCREEN 上の色調は, 印刷すると 濃淡ドットに表示される. ）。 \\
\hline 1150 & ．［注意］ \\
\hline 1160 & 原則として, 単色諧調でないと, 濃淡ドットが印刷されません。 . \\
\hline 1170 & SEL.CLの決め方を把握して下さい. \\
\hline 1180 & $\ldots \ldots \ldots \ldots$ \\
\hline 1190 & 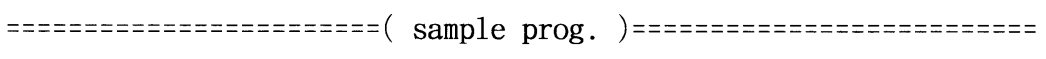 \\
\hline 1200 & WIDTH $80,25:$ CONSOLE $0,25,0,1:$ DEFINT I-N \\
\hline 1210 & SCREEN $3,3:$ CLS $3:$ SCREEN $3,0:$ COLOR 5 \\
\hline 1220 & PRINT "***** 15 階調の 中間色 表示プログラム *****”：PRINT \\
\hline 1230 & COLOR 7：PRINT ” 色諧調の表示だけなら 4,5 でも表示できます.” \\
\hline 1240 & PRINT ” しかし, 印刷するとシルエットになります ”：COLOR 6 \\
\hline 1250 & INPUT ” 色を決めて下さい(白,赤,緑,青/ 0,1,2,3,[4,5]) = ",SEL.CL \\
\hline 1255 & ' \\
\hline 1260 & GOSUB *COLOR .TILES \\
\hline 1265 & ' \\
\hline 1270 & INPUT ” 色諧調は幾つにしますか $(3-15 /$ blnk=7) = ",LC : CLS 1 \\
\hline 1280 & IF LC $<2$ THEN LC=7 \\
\hline 1290 & FOR K $=1$ TO LC $: K R=15 / L C *(K-1) \quad: \quad D S=240 / L C$ \\
\hline 1300 & $\mathrm{XS}=5^{+} \mathrm{DS} * \mathrm{~K} * 2$ \\
\hline 1310 & $\operatorname{LINE}(\mathrm{XS}-\mathrm{DS}+1, \mathrm{YS}-100)-(\mathrm{XS}+\mathrm{DS}, \mathrm{YS}+100), 7, \mathrm{~B}$ \\
\hline 1320 & IF XS<640 AND YS $<399$ THEN PAINT(XS, YS), TILE $(\mathrm{KR}+1), 7$ \\
\hline 1330 & IF K=1 THEN 1350 \\
\hline 1340 & $\operatorname{LINE}(\mathrm{XS}-\mathrm{DS}+1, \mathrm{YS}-100)-(\mathrm{XS}+\mathrm{DS}, \mathrm{YS}+100), 0, \mathrm{~B}$ \\
\hline 1350 & LOCATE $(\mathrm{XS}-5) / 8-1,5:$ PRINT K \\
\hline 1360 & LOCATE $($ XS-5)/8-1,19 : PRINT KR \\
\hline 1370 & NEXT K \\
\hline 1380 & LOCATE (XS-5)/8+5,19：PRINT ”色番号” \\
\hline 1390 & $\mathrm{cos}^{\circ} \mathrm{cos}$ \\
\hline 1400 & END \\
\hline
\end{tabular}




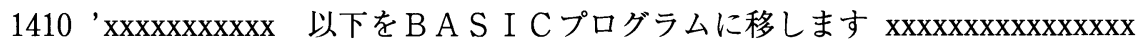

1420

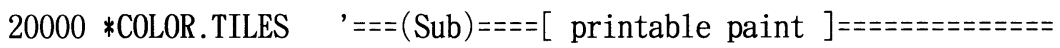

$20010^{\prime} \quad$ How to use? -..- - ex. line $(\mathrm{a}, \mathrm{b})-(\mathrm{c}, \mathrm{d}), \operatorname{TILE} \$(1-16)$

$20020^{\prime}$ color level 15

20030 DIM T\$ $(17,4), \operatorname{TILE} \$(16)$

$20040 \quad$ GOSUB $*$ DEF.COLOR

20050 FOR KR=1 T0 $16,0.0625=1.0 / 16$

$20060 \quad \mathrm{RR}=(\mathrm{KR}-1) * .0625$

20070 IF SEL.CL=0 THEN R=RR : $\mathrm{G}=\mathrm{R} \quad: \mathrm{B}=\mathrm{R}$

20080 IF SEL.CL=1 THEN R=RR : $\mathrm{G}=0 \quad: \mathrm{B}=0$

$20090 \quad$ IF SEL.CL $=2$ THEN R=0 : $\mathrm{G}=\mathrm{RR} \quad: \quad \mathrm{B}=0$

20100 IF SEL.CL=3 THEN R=0 : $\mathrm{G}=0 \quad: \mathrm{B}=\mathrm{RR}$

20110 IF SEL.CL=4 THEN R=RR : $\mathrm{G}=1$ ! -RR：B=0 ' unprintable

20120 IF SEL.CL=5 THEN R=RR : $\mathrm{G}=1$ !-RR：B=G ' unprintable

$20130 \quad$ GOSUB $*$ RGB.COLOR:TILE $\$($ KR $)=$ TILE $\$$

20140 NEXT KR

$20150 *$ RGB.COLOR

20160 IF $R<0$ OR $1<\mathrm{R}$ OR $\mathrm{B} \angle 0$ OR $1<\mathrm{B}$ OR $\mathrm{G}<0$ OR $1<\mathrm{G}$ THEN $\mathrm{R}=0: \mathrm{G}=0: \mathrm{B}=0$

$20170 \mathrm{R}=\mathrm{INT}(17 * \mathrm{R}): \mathrm{G}=\mathrm{INT}(17 * \mathrm{G}) \quad: \mathrm{B}=\mathrm{INT}(17 * \mathrm{~B})$

$20180 \mathrm{~T} 1 \$=\mathrm{T} \$(\mathrm{~B}, 1)+\mathrm{T} \$(\mathrm{R}, 1)+\mathrm{T} \$(\mathrm{G}, 1)$

$20190 \mathrm{~T} 2 \$=\mathrm{T} \$(\mathrm{~B}, 2)+\mathrm{T} \$(\mathrm{R}, 2)+\mathrm{T} \$(\mathrm{G}, 2)$

$20200 \mathrm{~T} 3 \$=\mathrm{T} \$(\mathrm{~B}, 3)+\mathrm{T} \$(\mathrm{R}, 3)+\mathrm{T} \$(\mathrm{G}, 3)$

$20210 \mathrm{~T} 4 \$=\mathrm{T} \$(\mathrm{~B}, 4)+\mathrm{T} \$(\mathrm{R}, 4)+\mathrm{T} \$(\mathrm{G}, 4)$

20220 TILE $\$=\mathrm{T} 1 \$+\mathrm{T} 2 \$+\mathrm{T} 3 \$+\mathrm{T} 4 \$$

20230 RETURN

$20240 *$ DEF.COLOR

20250 RESTORE *DATA.T

20260 FOR LIGHT=0 T0 17 : FOR ROW=1 T0 4

20270 READ T $\$$ : T\$ (LIGHT, ROW $)=$ CHR $\$(V A L(" \& H "+T \$))$

20280 NEXT: NEXT

20290 RETURN

20300 *DATA.T ' . . . . . . . . . . . . . .

20310 DATA $00,00,00,00,00,10,00,01,00,11,00,44$

20320 DATA $00, \mathrm{AA}, 00,44,00,55,00,55,55,22,55,00$

20330 DATA 88, 55,22, 55, 88, 55, AA, 55, 55, AA, 55, AA

20340 DATA 77, AA, 55, AA , 77, AA, DD , AA ,FF, AA, DD , AA

20350 DATA FF, AA, FF, AA, FF, AA, FF, BB, FF, EE, FF, BB

20360 DATA FF, EE, FF, FF, FF, FF, FF, FF, FF, FF, FF, FF

$20370:==== \pm= \pm=$ END OF COLOR.TILES 